\title{
Advances in Copper-Based Biomaterials With Antibacterial and Osteogenic Properties for Bone Tissue Engineering
}

\author{
Qiudi Shen ${ }^{1 \dagger}$, Yansong $\mathrm{Qi}^{2 \dagger}$, Yangzhi Kong ${ }^{1 \dagger}$, Huricha Bao ${ }^{2}$, Yifan Wang ${ }^{2}$, Alideertu Dong ${ }^{1 *}$, \\ Haixia $\mathrm{Wu}^{1 *}$ and Yongsheng $\mathrm{Xu}^{2 *}$ \\ ${ }^{1}$ College of Chemistry and Chemical Engineering, Inner Mongolia University, Hohhot, China, ${ }^{2}$ Department of Orthopedics, Inner \\ Mongolia People's Hospital, Hohhot, China
}

OPEN ACCESS

Edited by:

Weili Fu,

Sichuan University, China

Reviewed by:

Sara Ferraris,

Politecnico di Torino, Italy

Mark A. DeCoster,

Louisiana Tech University,

United States

*Correspondence:

Alideertu Dong

dongali@imu.edu.cn

Haixia Wu

chmwuhx@imu.edu.cn

Yongsheng $\mathrm{Xu}$

dlxyf@163.com

${ }^{+}$These authors have contributed equally to this work

Specialty section:

This article was submitted to Biomaterials,

a section of the journal

Frontiers in Bioengineering and

Biotechnology

Received: 15 October 2021 Accepted: 30 December 2021

Published: 20 January 2022

Citation:

Shen Q, Qi Y, Kong Y, Bao H, Wang Y, Dong A, Wu $\mathrm{H}$ and $\mathrm{Xu} Y$ (2022)

Advances in Copper-Based

Biomaterials With Antibacterial and Osteogenic Properties for Bone

Tissue Engineering.

Front. Bioeng. Biotechnol. 9:795425.

doi: 10.3389/fbioe.2021.795425
Treating bone defects coupled with pathogen infections poses a formidable challenge to clinical medicine. Thus, there is an urgent need to develop orthopedic implants that provide excellent antibacterial and osteogenic properties. Of the various types, copper-based biomaterials capable of both regenerating bone and fighting infections are an effective therapeutic strategy for bone tissue engineering and therefore have attracted significant research interest. This review examines the advantages of copper-based biomaterials for biological functions and introduces these materials' antibacterial mechanisms. We summarize current knowledge about the application of copper-based biomaterials with antimicrobial and osteogenic properties in the prevention and treatment of bone infection and discuss their potential uses in the field of orthopedics. By examining both broad and indepth research, this review functions as a practical guide to developing copper-based biomaterials and offers directions for possible future work.

Keywords: copper, biomaterials, antibacterial, osteogenic, bone tissue engineering

\section{INTRODUCTION}

Bone tissue is a mineralized, viscous, elastic connective tissue that plays an important role in the human body (Kasugai, 2003). As a rigid organ, bone not only supports and protects various other organs but also enables a range of activities (John et al., 2008). Bone tissue includes inorganic and organic components. The main inorganic component is hydroxyapatite, a mineral composed of calcium phosphate, and the main organic components are collagen and non-collagen fibers. The inorganic ingredients make bones strong, while collagen provides elasticity. As a living tissue, human bones continually engage in the processes of bone resorption and deposition, which are controlled by various cells: bone cells, osteoclasts, Gegenbaur cells, and lining cells. Bone cells are embedded in the bone matrix, while osteoclasts, Gegenbaur cells, and lining cells mainly exist on the bone surface and play an important role in bone turnover.

Bone defect refers to the absence of bone tissue at a specific anatomical location, which is generally the sequelae of high-intensity impact or trauma, tumor resection, infection, or revision surgery (Clarke, 2008; Barbieri et al., 2014; Wang and Yeung, 2017). Bone defects can be divided into small and large. Small bone defects without infection can achieve self-healing after debridement to remove nonviable tissues. At present, the main treatment methods for large bone defects are autologous, allogeneic, or bone graft substitutes (Van der Stok et al., 2011). Severe bone defects may lead to 
disability, affect the individual's ability to live and work, and cause serious social and economic burdens. Bone defect repair is one of the most common regenerative surgeries, with more than 200,000 bone transplants performed worldwide every year (Beuriat et al., 2019).

The most important factor to be controlled in the process of bone substitute implantation is the risk of infection, because the body responds to the interstitial environment around the implanted biomaterial as a fibrous inflammatory area with incomplete immune function, which is vulnerable to bacterial invasion (Campoccia et al., 2013). For elective surgery, the infection rate ranges from 0.7 to $4.2 \%$, and even as high as $30 \%$ in the case of third-degree open fractures (Clauss et al., 2010). Bone tissue infections are difficult to treat because they are located deep in the tissue and depend to some extent on the microorganisms involved. In addition, bone tissue necrosis may occur after infection or trauma, resulting in the body treating implants as foreign materials and leading to persistent, recurring infection (Calhoun et al., 2009). Patient healing time is prolonged, and repeat surgery may even be required.

In clinical settings, biomaterial-related infections are generally treated with systemic antibiotics, but high doses of antibiotics produce side effects and may lead to drug resistance in the host and bacteria. Hence, in recent years, research has focused on developing synthetic bone substitutes-biomaterials that are chemically modified in the synthesis process to meet specific biological needs. Because the skeleton is composed of a hydroxyapatite matrix and many trace elements, biomolecules, and cells, materials with complex chemical compositions are more suitable as bone substitutes than simple, pure materials (Ryan et al., 2019). Metal ions have attracted extensive attention because they do not cause drug resistance and can be delivered locally at the implantation site (Goudouri et al., 2014).

As a trace element in the human body, $\mathrm{Cu}$ not only has antibacterial properties and a variety of biological functions but also can promote angiogenesis (Gérard et al., 2010; Rath et al., 2016). Compared with growth factors, $\mathrm{Cu}$ has multiple advantages. First, it does not degrade in conventional processing and can remain stable under harsh conditions such as high temperature. In addition, copper has certain useful physical and chemical properties, including variable porosity, good mechanical strength, and crosslinking (Goh et al., 2014). It therefore could be used with other inorganic ions to generate new intelligent biomaterials that simulate the bone microenvironment. Because $\mathrm{Cu}$ has high antibacterial properties and low cytotoxicity, it has become a promising dopant that can confer the functional properties of bone and cartilage repair by guiding cell behavior and changing the physicochemical properties of biomaterials (Heidenau et al., 2005).

This review focuses on the application of copper combined with biomaterials in bone tissue and the associated antibacterial mechanisms. We also introduce the application of copper-based biomaterials with antibacterial and osteogenic properties in the prevention and treatment of bone infection.

\section{THE IMPORTANCE OF COPPER IN BONE TISSUE}

Copper is the third most abundant essential trace element in animals and humans, surpassed only by iron and zinc. It is well known that copper is involved in the growth and maturation of many tissues and proteins, especially bone collagen (Opsahl et al., 1982; Bernabucci et al., 2013). It also can promote bone development through a catalytic metabolic process that plays an important role in human bone growth and bone mass maintenance (Rodríguez et al., 2002; Tomaszewska et al., 2017). Many studies have shown that copper is very important for bone mineralization and osteoblasts (Danks, 1981; Lowe et al., 2002). As a significant cofactor of enzymes involved in the synthesis of various bone matrix components, copper can, for example, regulate the crosslinking formation by lysyl oxidase in connective tissue, promote the synthesis of collagen and keratin, and normalize the deposition of calcium and phosphorus to form bones on fibrils. (Linder and Hazegh-Azam, 1996).

Due to the important role of $\mathrm{Cu}$ in bone metabolism, severe $\mathrm{Cu}$ deficiency will lead to bone abnormalities. In this context, the World Health Organization, the American Institute of Medicine (IOM), the European Food Safety Agency, and other national and international organizations have issued dietary standards for $\mathrm{Cu}$ intake to maintain good health (Tuttle et al., 2019). According to the recommendations of the IOM, the copper intake for healthy adults is $0.9 \mathrm{mg} /$ day (Trumbo et al., 2001). Lack of copper in the body can lead to a variety of diseases, such as occipital angle syndrome, distal motor neuropathy, cardiovascular disease, and Menkes disease, the last of which may cause neuronal degeneration, abnormal connective tissue, abnormal lightening of hair color, and fragile bones (Wazir and Ghobrial, 2017).

In the field of tissue engineering, the use of copper can stimulate the biological characteristics required for endothelial cell proliferation during wound healing and promote the differentiation of mesenchymal stem cells into osteoblasts by upregulating the gene expression of vascular endothelial growth factor (Klatte-Schulz et al., 2012). $\mathrm{Cu}$ has been shown to differentiate and proliferate bone marrow mesenchymal stem cells obtained from postmenopausal women, increasing their ability to differentiate into bone and adipogenic lineages. Thus, copper has attracted attention because of its importance for bone tissue.

\section{ANTIBACTERIAL ACTION OF COPPER-BASED BIOMATERIALS}

In 2008, The United States Environmental Protection Agency recognized copper as a metallic antimicrobial effective against many disease-causing bacteria (Copper Development Associ, 2008). Studies have confirmed that copper has potential antibacterial activity against clinically relevant bacteria (Liochev and Fridovich, 2002). Infection is a matter of great concern in the medical field, so growing numbers of researchers in the field of biomaterials are focusing on the development of new copper-containing biomaterials, especially for orthopedics. 
Copper is added to different types of biomaterials, such as calcium phosphate bioceramics, biomedical ceramics, bioactive glass, biocomposites, and coating/alloy metals (titanium-based, stainless steel, and cobalt-based alloys) for research and antibacterial experiments.

Copper's modes of action are highly diverse, depending on the surrounding environment, and it operates through a variety of mechanisms. Antibacterial properties of copper arise from changes in the conformational structure of nucleic acids and proteins, as well as interference with oxidative phosphorylation and osmotic balance. One of the most important modes is based on the redox properties of copper. Under aerobic conditions, copper can change its oxidation state and exchange electrons with acceptor or donor groups (such as oxygen and sulfur residues). Copper can exert its antibacterial effect directly by reacting with biomolecules or indirectly by activating oxygen species. In the latter case, copper catalyzes the production of reactive oxygen species (ROS) through a Haber-Weiss reaction similar to Fenton's reaction (Grass et al., 2011). ROS themselves are extremely reactive when formed and quickly cause damage to surrounding biomolecules, particularly proteins, membranes, and DNA (Nandakumar et al., 2011).

Nandakumar and co-authors demonstrated the interaction of copper with proteins using a quantitative proteomics approach to identify the differential proteome profiles of Escherichia coli cells after exposure to metallic copper surfaces. Their results indicated that of the 509 proteins identified, 110 were differentially expressed after sub-lethal exposure, whereas 136 had significant differences in their abundance levels after lethal exposure to copper compared to unexposed cells (Ueda et al., 1980). The bactericidal potency of copper towards several bacteria with different cell envelope structures (Streptococcus lactis, E. coli, and P. aeruginosa) was found to be similar. The physical properties of a membrane are largely determined by its lipid composition, an important factor being the degree of fatty acid unsaturation. $\mathrm{Cu}^{2+}$ can interact with the SH-group, causing membrane damage and deactivation. $\mathrm{Cu}^{2+}$ also has a specific affinity for DNA and can bind to and disorder helical structures by crosslinking within and between strands (Wilks et al., 2005). In various studies, it was difficult to conduct antibacterial tests under the same conditions (that is, using the same medium and the same substance concentration in the medium), so it is impossible to know the specific copper release mechanism that led to the observation results. Nevertheless, it appears clear that the efficacy of contact killing was increased by higher copper content in alloys (Elguindi et al., 2009), higher temperature (Michels et al., 2009), and higher relative humidity (Wilson, 2018).

Metallic biomaterials such as titanium, cobalt and tantalum are widely used in orthopedics because of their good biocompatibility, unique mechanical properties and wear resistance. However, these biomaterials are limited in their practical application in bone tissue engineering due to their poor photocatalytic antibacterial properties in vivo. Copper is a well-known candidate with excellent bacteriakilling ability. It is very important to introduce a proper amount of copper into titanium and other metal materials to achieve copper alloy with excellent antibacterial performance and good biocompatibility for inhibiting bacterial infection in bone implants.
(Sehmi et al., 2015). In 2016, Liu et al. revealed the antimicrobial/ antibiofilm activities of $\mathrm{Ti}-\mathrm{Cu}$ alloy against orally specific bacterial species. From what is known so far, the bactericidal steps can be summarized as follows. First, $\mathrm{Cu}$ is released from a $\mathrm{Cu}$-doped surface material. After bacteria are exposed to copper ions, the permeability of their cell membranes changes, leading to a loss of cytoplasmic content. Next, ROS are produced, causing further cell damage by interacting with proteins and lipids, and finally, DNA is degraded. Consequently, the bacteria cannot breathe, eat, digest, or produce energy, and cell death ensues (Figure 1) (Liu et al., 2016).

The existing form of copper in biomaterials includes two main types: 1) copper ion and 2) copper metal, both which show excellent antibacterial properties, angiogenic and osteogenic ability. To date, numerous studies have investigated their mechanisms for the antibacterial action. For the former, when bacteria are exposed to copper ions, the permeability of cell membrane could be changed, resulting in content leakage and cell lysis. Besides, copper ions inhibit protein synthesis and DNA replication. As for latter, in addition to releasing copper ions to fight bacteria, it reacts with biological molecules on bacteria, and can also produce reactive oxygen species (ROS) to damage bacteria. Both copper metal and copper ion have been widely used in bone tissue engineering due to their excellent properties, however they suffer from high toxicity. So reducing the toxicity of copper-based biomaterials remains a great challenge (Karekar et al., 2019).

\section{APPLICATION OF COPPER-BASED BIOMATERIALS}

\section{Copper-Based Antibacterial Scaffolds}

In bone tissue engineering, scaffold biomaterials are a promising method for treating bone defects and bone infections, providing a temporary framework for the integration of new bone into the defect area. The scaffold biomaterial gradually degrades, being replaced by new bone tissue until the bone repair process is completed. In treatment practice, bone-promoting and antibacterial ingredients are added to support bone remodeling. Studies have found that $\mathrm{Cu}$ plays an important role in bone growth, and a lack of $\mathrm{Cu}$ can cause bone abnormalities and decreased bone strength. Doped copper scaffold biomaterials that can promote bone healing and resist infection thus have an important potential role in bone tissue engineering.

$\mathrm{Wu}$ et al. prepared a $\mathrm{Cu}$-containing bioactive glass (BG) scaffold with interconnected macropores and an ordered mesoporous structure. The scaffold enhanced angiogenesis and continuously release drugs, which significantly inhibited bacterial survival (Wu et al., 2013). Subha N. Rath et al. explored the biocompatibility and biological activity of $\mathrm{Cu}^{2+}$-doped BG scaffolds for bone marrow mesenchymal stem cells (BMSCs) and human dermal microvascular endothelial cells and found the scaffold was effective for BMSCs and not toxic. They also found that $\mathrm{Cu}^{2+}$ induced BMSCs to secrete vascular endothelial growth factor and thereby enhanced angiogenesis (Rath. et al., 2014). YiFan Goh et al. synthesized BG doped with $\mathrm{Cu}$ and $\mathrm{Ag}$, finding that 


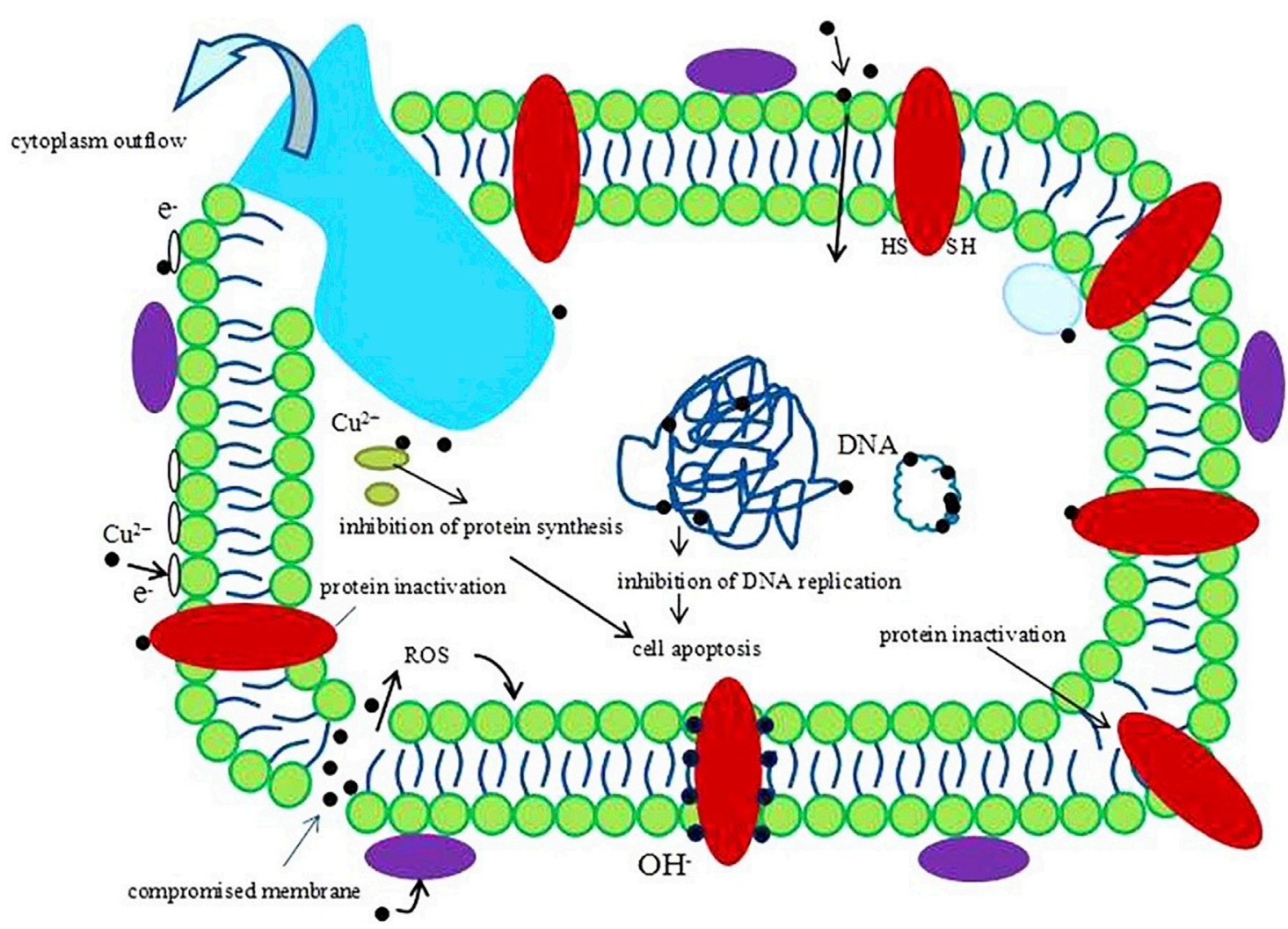

FIGURE 1 | A schematic image of one hypothesis about the antibacterial mechanism of $\mathrm{Cu}^{2+}$. Reprinted with permission from ref. (Liu et al., 2016) (Copyright 2016; Nature Publishing Group).
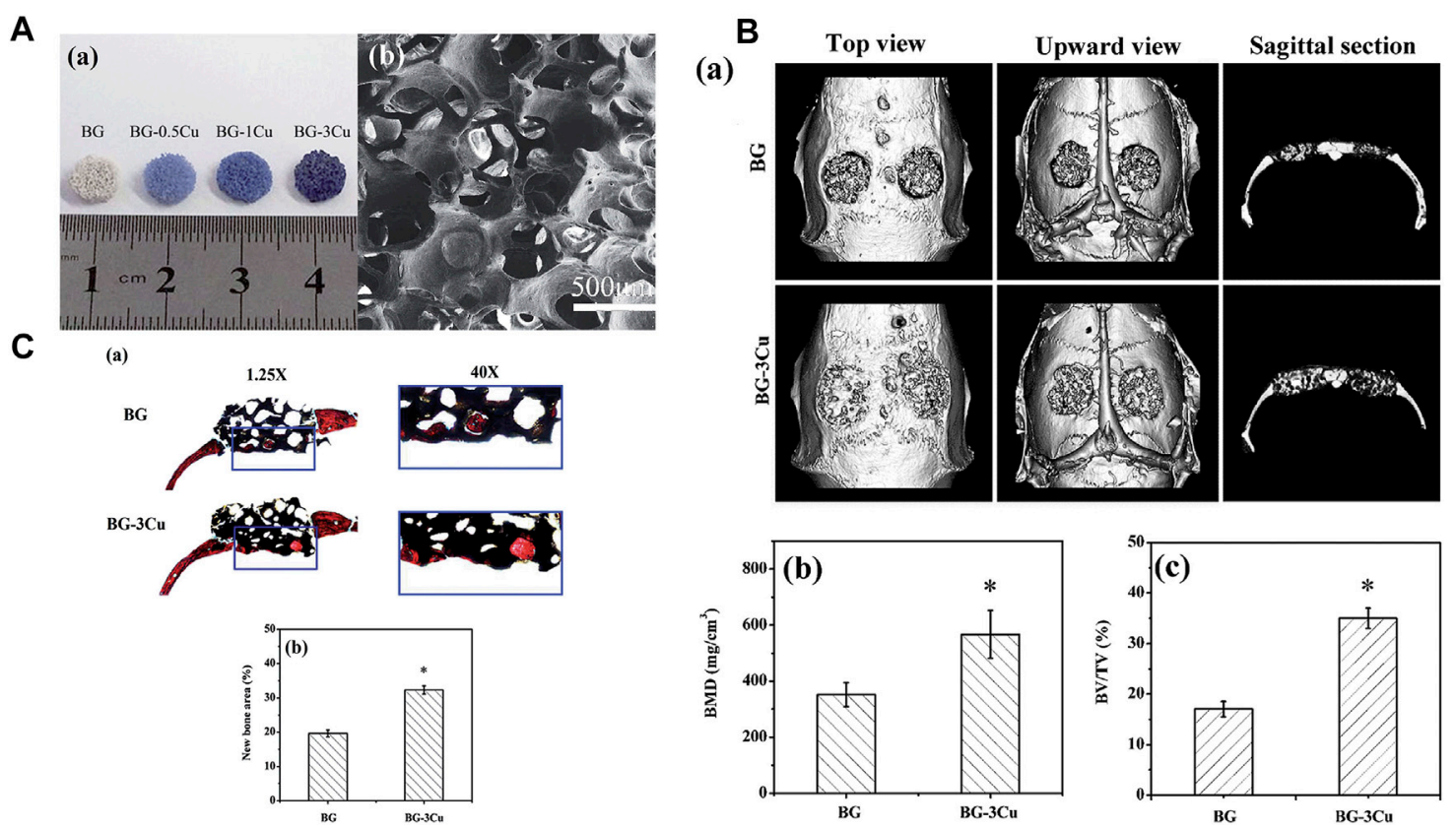

FIGURE 2 | (A) Optical images and SEM images of the scaffolds were obtained. (B) Microct evaluation of skull defects and unfilled bone regeneration in rats implanted with BG-3Cu and BG stents 8 weeks after implantation. (C) Transmitted light images of stained sections of rat skull defects implanted with BG-3Cu and BG scaffolds and unfilled defects 8 weeks after implantation. Reprinted with permission from ref. (Wang et al., 2014). (Copyright 2014; The Royal Society of Chemistry). 

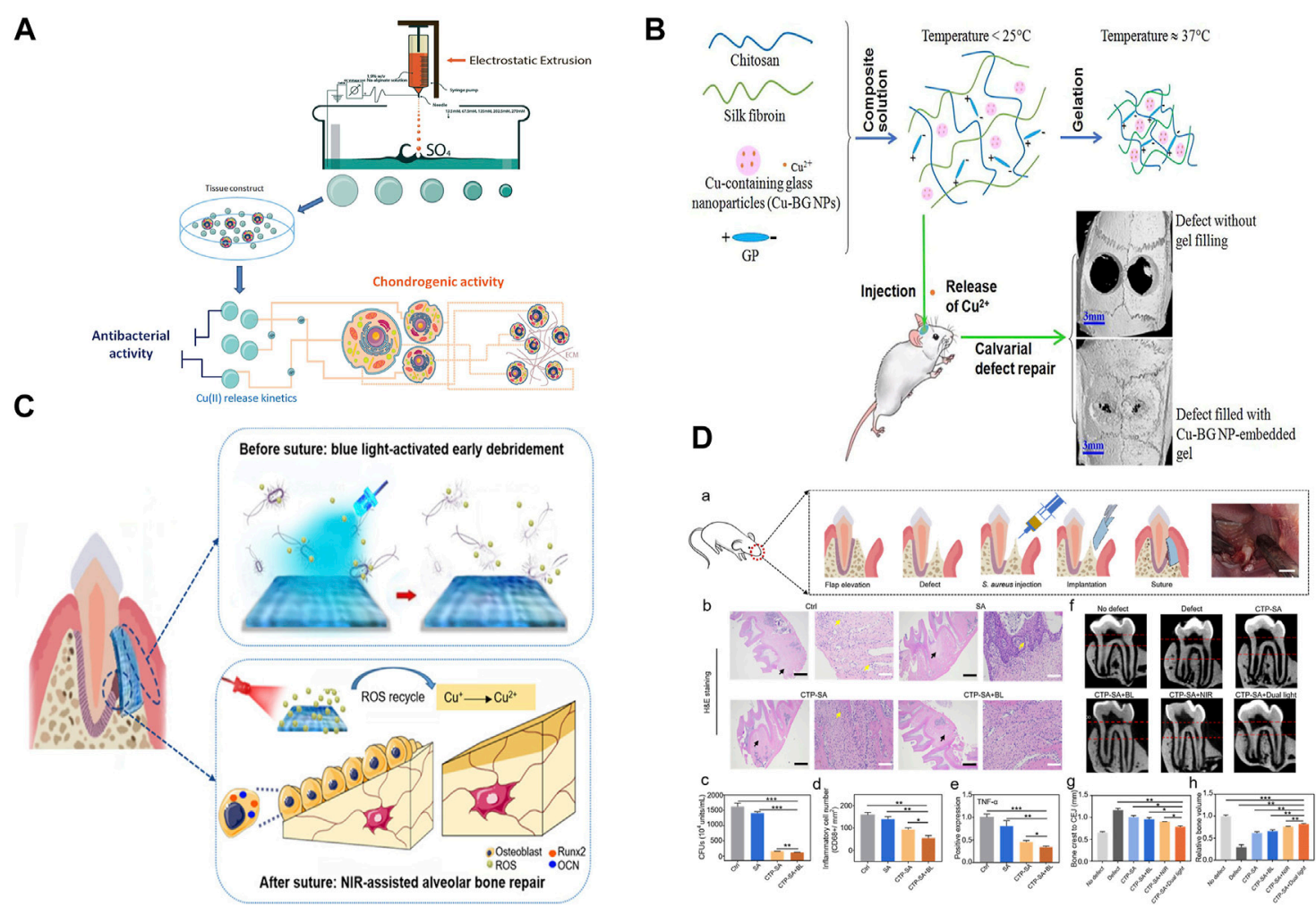

FIGURE 3 | (A) Synthesis and potential biomedical applications of copper alginate microspheres. (B) Development of a novel injectable hydrogel and its osteogenic application. (C) Schematic diagram of surgical construction of CTP-SA and GTR. (D) In vivo function of CTP-SA in GTR surgery. Panel (A) reprinted with permission from ref. (Madzovska-Malagurski et al., 2016) (Copyright 2016; IOP Publishing Ltd.). Panel (B) reprinted with permission from ref. (Bassett et al., 2014) (Copyright 2019; Elsevier). Panel (C) and panel (D) reprinted with permission from ref. (Xu et al., 2020) (Copyright 2020; American Chemical Society).

$\mathrm{Cu}$-doped BG exhibited longer ion release, making it a potential candidate for sustained long-term antibacterial performance (Goh et al., 2014). Mohamed Abudhahir et al. prepared biocomposite scaffolds of polycaprolactone, wollastonite, and $\mathrm{Cu}$ ions using electrospinning technology. The synthesized $\mathrm{PCL} / \mathrm{Cu}-\mathrm{Ws}$ scaffolds had good biocompatibility with mouse mesenchymal stem cells. In the presence of osteogenic mediators, the scaffold enhanced the expression of osteoblastspecific marker genes, indicating it had osteoconductivity. It also had a strong antibacterial effect on Staphylococcus aureus and E. coli (Abudhahir et al., 2021). Cu has also been doped into BG with osteoinductivity, biocompatibility, and biodegradability, then combined with a porous 3D collagen scaffold (CuBG-CS) to prepare a biological scaffold for osteomyelitis treatment. This not only promoted bone formation and angiogenesis but also inhibited S. aureus (Ryan et al., 2019).

Borate-based BGs are attracting attention as alternatives to silicate BGs because they more easily form porous scaffolds and degrade more quickly than silicate BGs. As shown in Figure 2, wang et al. used a polymer foam replication technique to prepare $\mathrm{Cu}$-doped borate glass scaffolds and found they had better bone regeneration and angiogenesis capabilities than undoped scaffolds (Wang et al., 2014). Subsequently, the effect of $\mathrm{Cu}$ doping on the properties of borosilicate BG was studied, and it was found that $\mathrm{Cu}$ ion doping made the glass network more stable, resulting in a lower ion release rate during the degradation process. At the same time, $\mathrm{Cu}$ ions have the potential for angiogenesis, so this copper-doped bioactive borosilicate glass scaffold material has good prospects for use in bone tissue engineering (Wang et al., 2016).

Ethylene-vinyl acetate (EVA) copolymer has excellent mechanical properties, good biocompatibility, and high adhesion but no antibacterial ability and needs further modification. Teno et al. synthesized a CuNP-modified EVA nanocomposite material. The CuNP doping gave it antibacterial ability against $\mathrm{DH} 5 \mathrm{a}$ E. coli and did not cause structural changes to or thermal degradation of the polymer (Teno et al., 2019).

As a common organic scaffold, PCL has the advantages of good biocompatibility, slow degradation rate, and low price. Mixing PCL with BG and copper metal nanoparticles can yield a nanofiber scaffold material that is nontoxic to fiber cells and has osteogenic potential (Akturk et al., 2021). Karuppannan et al. added $\mathrm{CuO}$ nanoparticles to PCL/gel fibers using a green synthesis method. The prepared CuONF had good mechanical properties and hydrophilicity and sustained in vitro drug release for $48 \mathrm{~h}$. At the same time, it had an antibacterial effect on wound pathogenic bacteria and supported the growth of fiber cells, which are effective in wound care (Karuppannan et al., 2021). 
TABLE 1 | Representative examples of copper-based antibacterial biomaterials.

\begin{tabular}{|c|c|c|c|c|c|}
\hline $\begin{array}{l}\text { Copper-based } \\
\text { biomaterials }\end{array}$ & Component & $\begin{array}{l}\text { Type } \\
\text { of } \mathrm{Cu}\end{array}$ & Result & Application & References \\
\hline \multirow[t]{9}{*}{$\begin{array}{l}\text { Antibacterial } \\
\text { scaffolds }\end{array}$} & Bioactive glass (BG) & $\mathrm{Cu}^{2+}$ & $\begin{array}{l}\text { Release of ibuprofen } \\
\text { and antibacterial }\end{array}$ & Infection of regenerated bone & Wu et al. (2013) \\
\hline & & $\mathrm{Cu}^{2+}$ & $\begin{array}{l}\text { Good bioactivity in } \\
\text { bone marrow tissue }\end{array}$ & Bone scaffold & Rath et al. (2014) \\
\hline & & $\mathrm{Cu}$ & In vitro antibacterial & Bone regeneration & Goh et al. (2014) \\
\hline & Polycaprolactone & $\mathrm{Cu}^{2+}$ & In vitro antibacterial & Bone tissue engineering & Abudhahir et al. (2021) \\
\hline & & $\mathrm{Cu}$ & $\begin{array}{l}\text { Have a positive effect } \\
\text { on fibroblast cell }\end{array}$ & Bone tissue engineering & Akturk et al. (2021) \\
\hline & & $\mathrm{CuO}$ & In vitro antibacterial & Antibacterial wound dressing & Karuppannan et al. (2021) \\
\hline & Collagen scaffold (CS) & $\mathrm{Cu}^{2+}$ & $\begin{array}{l}\text { Antibacterial and } \\
\text { enhancing bone healing }\end{array}$ & Infection osteomyelitis & Ryan et al. (2019) \\
\hline & Borate & $\mathrm{CuO}$ & $\begin{array}{l}\text { Stimulate angiogenesis } \\
\text { and regenerate bone }\end{array}$ & Healing bone defects & Wang et al. (2014), Wang et al. (2016) \\
\hline & $\begin{array}{l}\text { Ethylene-vinyl } \\
\text { acetate (EVA) }\end{array}$ & CuNPs & In vitro antibacterial & Antibacterial & Teno et al. (2019) \\
\hline \multirow[t]{3}{*}{$\begin{array}{l}\text { Antibacterial } \\
\text { hydrogels }\end{array}$} & Alginate & $\mathrm{Cu}^{2+}$ & In vitro antibacterial & $\begin{array}{l}\text { Antimicrobial wound } \\
\text { dressings and tissue } \\
\text { engineering scaffolds }\end{array}$ & $\begin{array}{l}\text { Queen et al. (2004), Lee and Mooney (2012), } \\
\text { Madzovska-Malagurski et al. (2016), Huang et al. } \\
\text { (2021) }\end{array}$ \\
\hline & & $\mathrm{Cu}^{2+}$ & Good bioactivity & $\begin{array}{l}\text { Bone tissue engineering } \\
\text { alternatives }\end{array}$ & Bassett et al. (2014) \\
\hline & $\mathrm{TiO}_{2} @ \mathrm{PDA}$ & $\mathrm{Cu}_{2} \mathrm{O}$ & $\begin{array}{l}\text { Antibacterial and } \\
\text { osteogenic }\end{array}$ & Periodontitis & Xu et al. (2020) \\
\hline $\begin{array}{l}\text { Antibacterial bone } \\
\text { cements }\end{array}$ & $\begin{array}{l}\text { Polymethyl } \\
\text { methacrylate (PMMA) }\end{array}$ & $\begin{array}{l}\mathrm{Cu} \\
\mathrm{Cu}^{2+}\end{array}$ & In vitro antibacterial & $\begin{array}{l}\text { Antibiofilm and bone tissue } \\
\text { engineering }\end{array}$ & $\begin{array}{l}\text { Uriu-Adams and Keen (2005), Tamayo et al. (2016), } \\
\text { Das et al. (2017), Burdușel et al. (2018), Miola et al. } \\
\text { (2018), Darder et al. (2020) }\end{array}$ \\
\hline
\end{tabular}

\section{Copper-Based Antibacterial Hydrogels}

Hydrogels with high oxygen permeability, water absorption and expansion, good biocompatibility, and other distinctive properties have been widely used in the biomedical field (Kopeček and Yang, 2007; Wang et al., 2019; Gao et al., 2020). Alginate saline gel produced by ion crosslinking of alginate with other ions has been applied to soft tissue implants and wound dressings because it requires only mild preparation conditions and has other attractive properties (Queen et al., 2004; Lee and Mooney, 2012; Huang et al., 2021). However, alginate saline gel has some limitations in practical applications because it has no biological activity or antibacterial properties. Levic et al. prepared $\mathrm{Cu}$-alginate hydrogels in the form of microbeads by adding copper to alginate by electrostatic extrusion. The results showed that microspheres loaded with $\sim 100 \mu \mathrm{mol} \mathrm{g}^{-1} \mathrm{Cu}$ (II) had high antibacterial activity against $E$. coli and $S$. aureus. Microspheres with low $\mathrm{Cu}(\mathrm{II})\left(\sim 60 \mu \mathrm{mol} \mathrm{g}{ }^{-1}\right)$ content released $\mathrm{Cu}$ (II) slowly enough to induce the proliferation of calf chondrocytes and promote chondrogenesis (Figure 3A) (Madzovska-Malagurski et al., 2016).

The use of metal ions, especially copper ions, in medical applications may present serious problems of acute local and systemic toxicity and lead to narrow therapeutic wounds. Hence, it is critical to achieve precise control and sustained release of copper ions in bone tissue applications. David et al. used alginate as a carrier for copper storage and as a copper ion diffusion barrier, doping copper materials into alginate brine gel microspheres through in situ mineralization and subsequent crosslinking with calcium. This method not only increased the amount of copper supported by alginate saline gel but also controlled the rate and duration of ion release. By altering the formulation of alginate saline gels containing both ionic and mineral copper, the total copper content was changed and the release time of $\mathrm{Cu}^{2+}$ could be adjusted from 5 to 32 days (Figure 3B) (Bassett et al., 2014).

Injectable hydrogels are also being developed to automatically match bone defects better (Wu et al., 2019). Wang et al. prepared sodium alginate hydrogel doped with cuprous oxide $\left(\mathrm{Cu}_{2} \mathrm{O}\right)$ nanoparticles and polydopamine (PDA)-coated titanium dioxide $\left(\mathrm{TiO}_{2} @ \mathrm{PDA}\right.$ ) nanoparticles to form a composite (CTP-SA) for guided tissue regeneration to treat periodontitis. The increased release of $\mathrm{Cu}^{2+}$ and the photothermal effect of $\mathrm{TiO}_{2} @ P D A$ when combined with NIR irradiation endowed the composite with osteogenic properties, which were beneficial for 
alveolar bone repair. This kind of bone implant material, which simultaneously enables dual customization of shape and function, has the potential for multiple applications in biomedicine (Figures 3C,D) (Xu et al., 2020).

\section{Copper-Based Antibacterial Bone Cements}

Bone cement based on polymethyl methacrylate (PMMA) is a unique biological material with the advantages of easy processing and good biological stability (Vaishya et al., 2013; Wekwejt et al., 2019). Antibiotic-loaded bone cement can greatly reduce the adhesion and proliferation of bacteria, but most antibiotics are not effective for continuous treatment after surgery, and longterm use can lead to the production of drug-resistant bacteria. It is therefore very important to develop new bone cements with excellent antibacterial properties. Metal nanoparticles such as $\mathrm{Cu}$ and $\mathrm{Ag}$ have good bactericidal properties and can be combined with PMMA to improve the bactericidal activity of bone cement. This is mainly due to the release of free metal ions, which cause direct damage to cell membranes and are absorbed by the cells, then produce reactive oxygen species. These processes can lead to bacterial death (Tamayo et al., 2016; Das et al., 2017; Burdușel et al., 2018; Darder et al., 2020).

Wekwejt et al. studied the bactericidal performance of PMMA modified with gentamicin, nanosilver, and nanocopper and found that compared with PMMA modified with gentamicin, PMMA modified with nanocopper had a higher bactericidal effect and better anti-biofilm performance but at the same time reduced the vitality of pulp stem cells (Miola et al., 2018). Miola et al. designed a new type of $\mathrm{Cu}$-doped bioactive glass powder composite cement, added it to PMMA-based cement with different viscosities, and characterized the prepared composite materials in terms of their biological activity, mechanical properties, and antibacterial properties. The results showed that the glass powder was evenly distributed on the surface of PMMA, and the composite cement had good biological activity and obvious antibacterial effect on Staphylococcus epidermidis strains (Uriu-Adams and Keen, 2005). PMMA itself is not degradable and has low adhesion ability, so modifications are very important for improving its biocompatibility and antibacterial properties. We summarized the application of copper-based biomaterials in bone tissue in Table 1, including antibacterial scaffolds, antibacterial hydrogels and antibacterial bone cement.

\section{CONCLUSION AND OUTLOOK}

This paper reviews the antibacterial properties and mechanism of copper-based biomaterials, as well as their application in bone tissue engineering, including antibacterial scaffolds, antibacterial hydrogels and antibacterial bone cement. Copper is an essential trace element involved in various physiological mechanisms of human beings. Many studies have shown that copper-based biomaterials have excellent antibacterial properties, angiogenesis and osteogenesis. So copper can be used as a promising dopant in combination with other biomaterials to effectively treat pathogenic infections in bone tissue, providing an interesting alternative to the extensive use of antibiotics and avoiding the development of antibiotic resistance. With regard to the role of copper in osteogenesis, it seems difficult to draw conclusions about effects on specific targets, since osteogenesis involves a very complex mechanism associated to multiple factors. Although beneficial therapeutic effects have been proved, the exact mechanism of action is still unclear, so it is difficult to accurately study and describe the effect of copperbased biomaterials on this physiological mechanism. The fact that more research is needed to clearly understand how copper interacts with the physiological processes of osteogenesis has important implications for orthopaedic applications.

The copper-based biomaterials show good antibacterial properties and low infection rates after bone implantation, copper deficiency and excessive accumulation however can lead to serious diseases and certain toxicity (Shim and Harris, 2003). For adults, the tolerable upper limit is $10 \mathrm{mg} /$ day and impairments occur above this level (Shenkin, 2010). Therefore, the biotoxicity of copper-based biomaterials should be evaluated before it is used in bone tissue engineering. It has been demonstrated that the toxicity of copperbased biomaterials is reduced by optimizing copper doping concentration, releasing curve or reducing metal particle size (Chen et al., 2021). At the same time, biocompatibility and antibacterial ability must also be achieved. At present, most experiments evaluate the toxicity of copper-based biomaterials by testing them with bone marrow stem cells, osteoblasts, and other cells, and using in vivo experiments in small animals (Prajapati et al., 2020). However, these do not simulate the human body's true response to toxicity, so more clinical trial results are needed.

\section{AUTHOR CONTRIBUTIONS}

QS and YK wrote the manuscript. YQ participated in critical revision of the manuscript for intellectual content. HB and YW sorted out and screened the relevant literatures. HW revised the paper, $\mathrm{AD}$ and $\mathrm{YX}$ designed the outline and revised the paper. All authors have read and approved the final version of this manuscript.

\section{FUNDING}

National Natural Science Foundation of China (22062017) and Natural Science Foundation of Inner Mongolia Autonomous Region (2019JQ03) by AD; National Natural Science Foundation of China (82172444) and the Science and Technology Plan Project of Inner Mongolia Autonomous Region (201802154,2021GG0127) by YX; Natural Science Foundation of Inner Mongolia Autonomous Region (2020MS03064) by HB. 


\section{REFERENCES}

Abudhahir, M., Saleem, A., Paramita, P., Kumar, S. D., Tze-Wen, C., Selvamurugan, N., et al. (2021). Polycaprolactone Fibrous Electrospun Scaffolds Reinforced with Copper Doped Wollastonite for Bone Tissue Engineering Applications. J. Biomed. Mater. Res. 109, 654-664. doi:10.1002/ jbm.b.34729

Akturk, A., Erol-Taygun, M., Goller, G., and Küçükbayrak, S. (2021). Optimization and Characterization of Poly( $\varepsilon$-Caprolactone) Nanofiber Mats Doped with Bioactive Glass and Copper Metal Nanoparticles. Chem. Pap. 75, 5929-5943. doi:10.1007/s11696-021-01777-7

Barbieri, L., Andreola, F., Bellucci, D., Cannillo, V., Lancellotti, I., Lugari, A., et al. (2014). Preliminary Studies on the Valorization of Animal Flour Ash for the Obtainment of Active Glasses. Ceramics Int. 40, 5619-5628. doi:10.1016/ j.ceramint.2013.10.156

Bassett, D. C., Madzovska, I., Beckwith, K. S., Melø, T. B., Obradovic, B., and Sikorski, P. (2014). Dissolution of Copper mineral Phases in Biological Fluids and the Controlled Release of Copper Ions from Mineralized Alginate Hydrogels. Biomed. Mater. 10, 015006. doi:10.1088/1748-6041/ 10/1/015006

Bernabucci, U., Basiricò, L., and Morera, P. (2013). Impact of Hot Environment on Colostrum and Milk Composition. Cell Mol Biol (Noisy-le-grand) 59, 67-83. doi:10.1170/T948

Beuriat, P-A., Lohkamp, L-N., Szathmari, A., Rousselle, C., Sabatier, I., Rocco, F. D., et al. (2019). Repair of Cranial Bone Defects in Children Using Synthetic Hydroxyapatite Cranioplasty (CustomBone). World Neurosurg. 129, e104-e113. doi:10.1016/j.wneu.2019.05.052

Burdușel, A-C., Gherasim, O., Grumezescu, A. M., Mogoantă, L., Ficai, A., and Andronescu, E. (2018). Biomedical Applications of Silver Nanoparticles: An Up-To-Date Overview. Nanomaterials 8, 681. doi:10.3390/nano8090681

Calhoun, J., Manring, M. M., and Shirtliff, M. (2009). Osteomyelitis of the Long Bones. Semin. Plast. Surg. 23, 059-072. doi:10.1055/s-0029-1214158

Campoccia, D., Montanaro, L., and Arciola, C. R. (2013). A Review of the Clinical Implications of Anti-Infective Biomaterials and Infection-Resistant Surfaces. Biomaterials 34, 8018-8029. doi:10.1016/j.biomaterials.2013.07.048

Chen, Z-Y., Gao, S., Zhang, Y-W., Zhou, R-B., and Zhou, F. (2021). Antibacterial Biomaterials in Bone Tissue Engineering. J. Mater. Chem. B. 9, 2594-2612. doi:10.1039/d0tb02983a

Clarke, B. (2008). Normal Bone Anatomy and Physiology. Clin. J. Am. Soc. Nephrol. 3, S131-S139. doi:10.2215/cjn.04151206

Clauss, M., Trampuz, A., Borens, O., Bohner, M., and Ilchmann, T. (2010). Biofilm Formation on Bone Grafts and Bone Graft Substitutes: Comparison of Different Materials by a Standard in vitro Test and Microcalorimetry. Acta Biomater. 6, 3791-3797. doi:10.1016/j.actbio.2010.03.011

Copper Development Associtaion Inc (2008) U.S. EPA Approves Registration of Antimicrobial Copper Alloys. Available at: https://www.copper.org/about/ pressreleases/2008/pr2008_Mar_25.htm Accessed: March 25, 2008.

Danks, D. M. (1981). Biological Roles of Copper. Ann. Intern. Med. 79, 235-257.

Darder, M., Karan, A., Real, G. D., and DeCoster, M. A. (2020). Cellulose-based Biomaterials Integrated with Copper-Cystine Hybrid Structures as Catalysts for Nitric Oxide Generation. Mater. Sci. Eng. C 108, 110369. doi:10.1016/ j.msec.2019.110369

Das, B., Dash, S. K., Mandal, D., Ghosh, T., Chattopadhyay, S., Tripathy, S., et al. (2017). Green Synthesized Silver Nanoparticles Destroy Multidrug Resistant Bacteria via Reactive Oxygen Species Mediated Membrane Damage. Arabian J. Chem. 10, 862-876. doi:10.1016/j.arabjc.2015.08.008

Elguindi, J., Wagner, J., and Rensing, C. (2009). Genes Involved in Copper Resistance Influence Survival ofPseudomonas Aeruginosaon Copper Surfaces. J. Appl. Microbiol. 106, 1448-1455. doi:10.1111/j.13652672.2009.04148.x

Gao, Y., Li, Z., Huang, J., Zhao, M., and Wu, J. (2020). In Situ formation of Injectable Hydrogels for Chronic Wound Healing. J. Mater. Chem. B 8, 8768-8780. doi:10.1039/d0tb01074j

Gérard, C., Bordeleau, L.-J., Barralet, J., and Doillon, C. J. (2010). The Stimulation of Angiogenesis and Collagen Deposition by Copper. Biomaterials 31, 824-831. doi:10.1016/j.biomaterials.2009.10.009
Goh, Y.-F., Alshemary, A. Z., Akram, M., Abdul Kadir, M. R., and Hussain, R. (2014). Bioactive Glass: AnIn-VitroComparative Study of Doping with Nanoscale Copper and Silver Particles. Int. J. Appl. Glass. Sci. 5, 255-266. doi:10.1111/ijag.12061

Goudouri, O.-M., Kontonasaki, E., Lohbauer, U., and Boccaccini, A. R. (2014). Antibacterial Properties of Metal and Metalloid Ions in Chronic Periodontitis and Peri-Implantitis Therapy. Acta Biomater. 10, 3795-3810. doi:10.1016/ j.actbio.2014.03.028

Grass, G., Rensing, C., and Solioz, M. (2011). Metallic Copper as an Antimicrobial Surface. Appl. Environ. Microbiol. 77, 1541-1547. doi:10.1128/aem.02766-10

Heidenau, F., Mittelmeier, W., Detsch, R., Haenle, M., Stenzel, F., Ziegler, G., et al. (2005). A Novel Antibacterial Titania Coating: Metal Ion Toxicity and in vitro Surface Colonization. J. Mater. Sci. Mater. Med. 16, 883-888. doi:10.1007/ s10856-005-4422-3

Huang, W., Cheng, S., Wang, X., Zhang, Y., Chen, L., and Zhang, L. (2021). Noncompressible Hemostasis and Bone Regeneration Induced by an Absorbable Bioadhesive Self-Healing Hydrogel. Adv. Funct. Mater. 31, 2009189. doi:10.1002/adfm.202009189

John, P. B., Lawrence, R., and John, M. (2008). Modeling and Remodeling. London: Academic Press.

Karekar, N., Karan, A., Khezerlou, E., Prajapati, N., Pernici, C. D., Murray, T. A., et al. (2019). Self-Assembled Metal-Organic Biohybrids (MOBs) Using Copper and Silver for Cell Studies. Nanomaterials 9, 1282. doi:10.3390/nano9091282

Karuppannan, S. K., Ramalingam, R., Mohamed Khalith, S. B., Musthafa, S. A., Dowlath, M. J. H., Munuswamy-Ramanujam, G., et al. (2021). Copper Oxide Nanoparticles Infused Electrospun Polycaprolactone/Gelatin Scaffold as an Antibacterial Wound Dressing. Mater. Lett. 294, 129787. doi:10.1016/ j.matlet.2021.129787

Kasugai, S. (2003). Characteristics of Periodontal Ligament and Regeneration of Periodontal Tissue. Inflamm. Regen. 23, 34-38. doi:10.2492/jsir.23.34

Klatte-Schulz, F., Scheibel, M., Pauly, S., Scheibel, M., Greiner, S., Gerhardt, C., et al. (2012). Influence of Age on the Cell Biological Characteristics and the Stimulation Potential of Male Human Tenocyte-Like Cells. eCM 24, 74-89. doi:10.22203/ecm.v024a06

Kopeček, J., and Yang, J. (2007). Hydrogels as Smart Biomaterials. Polym. Inter. 56, 1078-1098. doi:10.1002/pi.2253

Lee, K. Y., and Mooney, D. J. (2012). Alginate: Properties and Biomedical Applications. Prog. Polym. Sci. 37, 106-126. doi:10.1016/ j.progpolymsci.2011.06.003

Linder, M. C., and Hazegh-Azam, M. (1996). Copper Biochemistry and Molecular Biology. Am. J. Clin. Nutr. 63, 797S-811S. doi:10.1093/ajen/63.5.797

Liochev, S. I., and Fridovich, I. (2002). The Haber-Weiss Cycle-70 Years Later: An Alternative View. Redox Rep. 7, 55-57. doi:10.1179/135100002125000190

Liu, R., Memarzadeh, K., Chang, B., Zhang, Y., Ma, Z., Allaker, R. P., et al. (2016). Antibacterial Effect of Copper-Bearing Titanium alloy (Ti-Cu) against Streptococcus Mutans and Porphyromonas Gingivalis. Sci. Rep. 6, 29985. doi:10.1038/srep29985

Lowe, N. M., Fraser, W. D., and Jackson, M. J. (2002). Is There a Potential Therapeutic Value of Copper and Zinc for Osteoporosis? Proc. Nutr. Soc. 61, 181-185. doi:10.1079/pns2002154

Madzovska-Malagurski, I., Vukasinovic-Sekulic, M., Kostic, D., and Levic, S. (2016). Towards Antimicrobial yet Bioactive Cu-Alginate Hydrogels. Biomed. Mater. 11, 035015. doi:10.1088/1748-6041/11/3/035015

Michels, H. T., Noyce, J. O., and Keevil, C. W. (2009). Effects of Temperature and Humidity on the Efficacy of Methicillin-resistantStaphylococcus Aureuschallenged Antimicrobial Materials Containing Silver and Copper. Lett. Appl. Microbiol. 49, 191-195. doi:10.1111/j.1472-765x.2009.02637.x

Miola, M., Cochis, A., Kumar, A., Arciola, C., Rimondini, L., and Verné, E. (2018). Copper-Doped Bioactive Glass as Filler for PMMA-Based Bone Cements: Morphological, Mechanical, Reactivity, and Preliminary Antibacterial Characterization. Materials 11, 961. doi:10.3390/ma11060961

Nandakumar, R., Espirito Santo, C., Madayiputhiya, N., and Grass, G. (2011) Quantitative Proteomic Profiling of the Escherichia coli Response to Metallic Copper Surfaces. Biometals 24, 429-444. doi:10.1007/s10534-011-9434-5

Opsahl, W., Zeronian, H., Ellison, M., Lewis, D., Rucker, R. B., and Riggins, R. S. (1982). Role of Copper in Collagen Cross-Linking and its Influence on Selected Mechanical Properties of Chick Bone and Tendon. J. Nutr. 4, 708-716. doi:10.1093/jn/112.4.708 
Prajapati, N., Karan, A., Khezerlou, E., and DeCoster, M. A. (2020). The Immunomodulatory Potential of Copper and Silver Based Self-Assembled Metal Organic Biohybrids Nanomaterials in Cancer Theranostics. Front. Chem. 8, 629835. doi:10.3389/fchem.2020.629835

Queen, D., Orsted, H., Sanada, H., and Sussman, G. (2004). A Dressing History. Inter.Wound J. 1, 59-77. doi:10.1111/j.1742-4801.2004.0009.x

Rath., S. N., Brandl, A., Hiller, D., Hoppe, A., Gbureck, U., Horch, R. E., et al. (2014). Bioactive Copper-Doped Glass Scaffolds Can Stimulate Endothelial Cells in Co-Culture in Combination with Mesenchymal Stem Cells. PLoS ONE 9, e113319. doi:10.1371/journal.pone.0113319

Rath, S. N., Nooeaid, P., Arkudas, A., Beier, J. P., Strobel, L. A., Brandl, A., et al. (2016). Adipose- and Bone Marrow-Derived Mesenchymal Stem Cells Display Different Osteogenic Differentiation Patterns in 3D Bioactive Glass-Based Scaffolds. J. Tissue Eng. Regen. Med. 10, E497-E509. doi:10.1002/term.1849

Rodríguez, J. P., Ríos, S., and González, M. (2002). Modulation of the Proliferation and Differentiation of Human Mesenchymal Stem Cells by Copper. J. Cell. Biochem. 85, 92-100. doi:10.1002/jcb.10111

Ryan, E. J., Ryan, A. J., González-Vázquez, A., Philippart, A., Ciraldo, F. E., Hobbs, C., et al. (2019). Collagen Scaffolds Functionalised with Copper-Eluting Bioactive Glass Reduce Infection and Enhance Osteogenesis and Angiogenesis Both in vitro and in vivo. Biomaterials 197, 405-416. doi:10.1016/j.biomaterials.2019.01.031

Sehmi, S. K., Noimark, S., Weiner, J., Allan, E., MacRobert, A. J., and Parkin, I. P. (2015). Potent Antibacterial Activity of Copper Embedded into Silicone and Polyurethane. ACS Appl. Mater. Inter. 7, 22807-22813. doi:10.1021/acsami.5b08665

Shenkin, A. (2010). Dietary Reference Values for Vitamin A, Vitamin K, Arsenic, boron, Chromium, Copper, Iodine, Iron, Manganese, Molybdenum, Nickel, Silicon, Vanadium and Zinc. J. Hum. Nutr. Diet. 16, 199-200. doi:10.1046/ j.1365-277X.2003.00439.x

Shim, H., and Harris, Z. L. (2003). Genetic Defects in Copper Metabolism. J. Nutr. 133, 1527S-1531S. doi:10.1093/jn/133.5.1527S

Tamayo, L., Azócar, M., Kogan, M., Riveros, A., and Páez, M. (2016). Copperpolymer Nanocomposites: An Excellent and Cost-Effective Biocide for Use on Antibacterial Surfaces. Mater. Sci. Eng. C 69, 1391-1409. doi:10.1016/ j.msec.2016.08.041

Teno, J., Corral, A., Gorrasi, G., Sorrentino, A., and Benito, J. G. (2019). Fibrous Nanocomposites Based on EVA40 Filled with $\mathrm{Cu}$ Nanoparticles and Their Potential Antibacterial Action. Mater. Today Commun. 20, 100581. doi:10.1016/j.mtcomm.2019.100581

Tomaszewska, E., Dobrowolski, P., Kwiecień, M., Winiarska-Mieczan, A., Tomczyk, A., and Muszyński, S. (2017). The Influence of the Dietary CuGlycine Complex on the Histomorphology of Cancellous Bone, Articular Cartilage, and Growth Plate as Well as Bone Mechanical and Geometric Parameters Is Dose Dependent. Biol. Trace. Elem. Res. 178, 54-63. doi:10.1007/s12011-016-0894-x

Trumbo, P., Yates, A. A., Schlicker, S., and Poos, M. (2001). Dietary Reference Intakes. J. Am. Diet. Assoc. 101, 294-301. doi:10.1016/s0002-8223(01) 00078-5

Tuttle, R. R., Rubin, H. N., Rithner, C. D., Finke, R. G., and Reynolds, M. M. (2019). Copper ion vs copper metal-organic framework catalyzed NO release from bioavailable S -Nitrosoglutathione en route to biomedical applications: Direct $1 \mathrm{H} \mathrm{NMR}$ monitoring in water allowing identification of the distinct, true reaction stoichiometries and thiol dependencies. J. Inorg. Biochem. 199, 110760. doi:10.1016/j.jinorgbio.2019.110760

Ueda, K., Morita, J., Yamashita, K., and Komano, T. (1980). Inactivation of Bacteriophage Phi X174 by Mitomycin C in the Presence of Sodium Hydrosulfite and Cupric Ions. Chem. Biol. Interact 29, 145-158. doi:10.1016/0009-2797(80)90029-0

Uriu-Adams, J. Y., and Keen, C. L. (2005). Copper, Oxidative Stress, and Human Health. Mol. Aspects Med. 26, 268-298. doi:10.1016/j.mam.2005.07.015
Vaishya, R., Chauhan, M., and Vaish, A. (2013). Bone Cement. J. Clin. Orthopaedics Trauma 4, 157-163. doi:10.1016/j.jcot.2013.11.005

Van der Stok, J., Van Lieshout, E. M. M., El-Massoudi, Y., Van Kralingen, G. H., and Patka, P. (2011). Bone Substitutes in the Netherlands - A Systematic Literature Review. Acta Biomater. 7, 739-750. doi:10.1016/j.actbio.2010.07.035

Wang, H., Zhao, S., Xiao, W., Xue, J., Shen, Y., Zhou, J., et al. (2016). Influence of $\mathrm{Cu}$ Doping in Borosilicate Bioactive Glass and the Properties of its Derived Scaffolds. Mater. Sci. Eng. C 58, 194-203. doi:10.1016/j.msec.2015.08.027

Wang, H., Zhao, S., Zhou, J., Shen, Y., Huang, W., Zhang, C., et al. (2014). Evaluation of Borate Bioactive Glass Scaffolds as a Controlled Delivery System for Copper Ions in Stimulating Osteogenesis and Angiogenesis in Bone Healing. J. Mater. Chem. B 2, 8547-8557. doi:10.1039/c4tb01355g

Wang, K., Hao, Y., Wang, Y., Chen, J., Mao, L., Deng, Y., et al. (2019). Functional Hydrogels and Their Application in Drug Delivery, Biosensors, and Tissue Engineering. Int. J. Polym. Sci. 2019, 1-14. doi:10.1155/2019/3160732

Wang, W., and Yeung, K. W. K. (2017). Bone Grafts and Biomaterials Substitutes for Bone Defect Repair: A Review. Bioact. Mater. 2, 224-247. doi:10.1016/ j.bioactmat.2017.05.007

Wazir, S. M., and Ghobrial, I. (2017). Copper Deficiency, a New Triad: Anemia, Leucopenia, and Myeloneuropathy. J. Community Hosp. Intern. Med. Perspect. 7, 265-268. doi:10.1080/20009666.2017.1351289

Wekwejt, M., Michno, A., Truchan, K., Pałubicka, A., Świeczko-Żurek, B., Osyczka, A. M., et al. (2019). Antibacterial Activity and Cytocompatibility of Bone Cement Enriched with Antibiotic, Nanosilver, and Nanocopper for Bone Regeneration. Nanomaterials 9, 1114. doi:10.3390/nano9081114

Wilks, S. A., Michels, H., and Keevil, C. W. (2005). The Survival of Escherichia coli O157 on a Range of Metal Surfaces. Int. J. Food Microbiol. 105, 445-454. doi:10.1016/j.ijfoodmicro.2005.04.021

Wilson, J. (2018). Metallic Biomaterials: State of the Art and New Challenges. New York, NY: Woodhead Publishing.

Wu, C., Zhou, Y., Xu, M., Han, P., Chen, L., Chang, J., et al. (2013). CopperContaining Mesoporous Bioactive Glass Scaffolds with Multifunctional Properties of Angiogenesis Capacity, Osteostimulation and Antibacterial Activity. Biomaterials 34, 422-433. doi:10.1016/j.biomaterials.2012.09.066

Wu, J., Zheng, K., Huang, X., Liu, J., Liu, H., Boccaccini, A. R., et al. (2019). Thermally Triggered Injectable Chitosan/Silk Fibroin/Bioactive Glass Nanoparticle Hydrogels for Iin-Ssitu Bone Formation in Rat Calvarial Bone Defects. Acta Biomater. 91, 60-71. doi:10.1016/j.actbio.2019.04.023

Xu, Y., Zhao, S., Weng, Z., Zhang, W., Wan, X., Cui, T., et al. (2020). Jelly-Inspired Injectable Guided Tissue Regeneration Strategy with Shape Auto-Matched and Dual-Light-Defined Antibacterial/Osteogenic Pattern Switch Properties. ACS Appl. Mater. Inter. 12, 54497-54506. doi:10.1021/acsami.0c18070

Conflict of Interest: The authors declare that the research was conducted in the absence of any commercial or financial relationships that could be construed as a potential conflict of interest.

Publisher's Note: All claims expressed in this article are solely those of the authors and do not necessarily represent those of their affiliated organizations, or those of the publisher, the editors, and the reviewers. Any product that may be evaluated in this article, or claim that may be made by its manufacturer, is not guaranteed or endorsed by the publisher.

Copyright (c) 2022 Shen, Qi, Kong, Bao, Wang, Dong, Wu and Xu. This is an openaccess article distributed under the terms of the Creative Commons Attribution License (CC BY). The use, distribution or reproduction in other forums is permitted, provided the original author(s) and the copyright owner(s) are credited and that the original publication in this journal is cited, in accordance with accepted academic practice. No use, distribution or reproduction is permitted which does not comply with these terms. 